\title{
Complexity-based social-ecological systems research: philosophical foundations and practical implications
} Rika Preiser, ${ }^{1}$ Maja Schlüter, ${ }^{2}$ Reinette Biggs, ${ }^{1,2}$ María Mancilla
García, ${ }^{2}$ Jamila Haider, ${ }^{2}$ Tilman Hertz ${ }^{2}$ and Louis Klein

${ }^{1}$ CENTRE FOR SUSTAINABILITY TRANSITIONS, STELLENBOSCH UNIVERSITY, STELLENBOSCH, SOUTH AFRICA
2STOCKHOLM RESILIENCE CENTRE, STOCKHOLM UNIVERSITY, STOCKHOLM, SWEDEN AUSTRIA

\section{Introduction}

The social-ecological systems (SES) literature now widely recognises that SES can be characterised as intertwined complex adaptive systems (CAS) (Berkes, Colding, and Folke 2003; Norberg and Cumming 2008, Schoon and Van der Leeuw 2015; Preiser et al. 2018; De Vos, Biggs, and Preiser 2019; Schlüter et al. 2019a). However, understanding the features and behaviour of CAS poses a huge challenge for traditional disciplinary approaches, as researchers are called to study phenomena that are difficult to delineate, define and analyse. This difficulty is related to the fact that CAS have context-sensitive adaptive capacities, which come about as a result of multiple and non-linear recursive causal interactions that cause spill-over effects across different spatial and temporal scales (Levin 2000). Despite the growing scientific understanding that nature and humans in the Anthropocene are intertwined, the tools and technologies we have to measure human influence and effects on natural environments fall short when having to deal with uncertainty and the emergent nature of CAS.

As mentioned in Chapter 1, the field of SES research developed as a response to the growing consensus that there is a need for broader and more integrative approaches to understand and study the interlinked nature of human-environment systems and the challenges to which they give rise (Bammer et al. 2020). There is growing recognition that our traditional scientific frameworks as applied in single disciplines are not adequate for capturing the complexity of global challenges (Wells 2013; Schoon and Van der Leeuw 2015). The speed and scale at which sustainability challenges emerge and change motivate us to find ways to more deeply understand the nature of the problems we face. Building on this recognition, SES research draws on a diverse range of disciplines to form an integrated and multi-disciplinary approach to researching the intertwined nature of social-ecological interactions (Berkes and Folke 1998). 
Studying the history of ideas and events that informed our current understanding of SES reveals that foundational SES scholars worked in groups of interdisciplinary research projects or networks such as the Resilience Alliance (RA) network, the Millennium Ecosystem Assessment (MA) and newly created international institutes to address the wide-ranging challenges posed by the aspirations and challenges of achieving sustainability. Interdisciplinary collaboration in the early 1990s and 2000s allowed the ideas of leading complexity scientists (Holland 1995), physicists (Gell-Mann 1994; Prigogine 1996), biologists (Rosen 1991; Kauffman 1993), ecologists (Levin 1998, 2000; Holling 2001) and economists (Ostrom 1990; Arthur 1999) to converge at places like the International Institute of Applied Systems Analysis (IIASA) in Austria, the Santa Fe Institute in New Mexico, USA, and the Beijer Institute of Ecological Economics in Sweden. Under the impetus of these collaborations, a growing community of scientists worldwide was inspired to develop new theoretical frameworks and experimental approaches to explain why human-nature systems should be viewed as living CAS that operate under conditions marked by non-equilibrium. Within resilience thinking, for example, the 'Panarchy' framework (Gunderson and Holling 2002) demonstrates the way in which living systems simultaneously persist and innovate or adapt, and reveals how fast and slow, small and big events and processes can transform ecosystems, organisms and human societies (Holling 2004). From a deeper understanding of how living systems simultaneously foster persistence and renew themselves through evolutionary processes that include cycles of growth and collapse, the intertwined nature of adaptive cycles across scales proved a useful point of departure for positing that SES are complex adaptive systems (Gunderson and Holling 2002; Berkes, Colding, and Folke 2003).

Acknowledging the complex and adaptive nature of living systems, SES research proposes a more integrated approach for studying and engaging with the intertwined nature of human-environment relations. Complex adaptive systems thinking provides a way of bridging the study of social and biophysical sciences to understand the features of these phenomena, the interlinked patterns that emerge and the novelty that is created as a result. It also forms the foundation of many of the new integrative approaches and frameworks in SES research (Berkes and Folke 1998; Holling 2001; Folke et al. 2004; Liu et al. 2007; Levin et al. 2013; Rogers et al. 2013; Schoon and Van der Leeuw 2015; Folke 2016; Preiser et al. 2018; Clark and Harley. 2019; Schlüter et al. 2019a). Key areas of SES research such as resilience, adaptability, transformability and stewardship are all informed by the underlying assumptions that are based on an understanding of the characteristics and dynamics of CAS (Folke et al. 2004; Walker et al. 2004; Levin et al. 2013; Folke 2016). Students who enter the field of SES research take this conceptual foundation for granted. Often, the importance of understanding SES as complex adaptive systems and the implications of doing so, as argued in the late 1990s and early 2000s, are not that deeply emphasised any more.

This chapter provides some background to how ideas about and the understanding of CAS developed, and how the recognition that SES are complex adaptive systems introduces a mindshift in how we understand the nature of the world, and what tools and methods we can use to study and understand SES. This chapter discusses the scientific assumptions that inform our understanding of CAS, what these mean for grounding a CAS-based understanding of reality, and how this shift in focus influences the theories, frameworks and methods that we use to study SES and make decisions about how to act and govern complex adaptive SES.

\section{Origins of the concept of complexity and a complexity-based worldview}

The proliferation of ideas relating to the concepts of 'complexity' and 'CAS' is relatively recent in the history of scientific ideas. Publications of classic papers that describe notions of complexity 
in scientific terms began in the 1940s (Midgley 2003). The work of Waldrop (1993) and Lewin (1993) offered a more popular understanding of complexity that could be applied over a wide range of disciplines. Yet, tracing the conceptual and historical roots of the notion of 'complexity', and the original moment at which one would say that a 'theory of complexity' was born, remains a rather daunting and somewhat impossible task. A search through the ever-growing literature on the study of complex systems reveals that there is no unifying 'theory of complexity' (Chu, Strand, and Fjelland 2003), and that one can trace several conceptual origins rooted in different disciplines that have been combined to form a collective understanding of what we have come to know as 'complexity theory'. A closer investigation into the development of CAS thinking reveals that one should rather speak of 'theories of complexity' (Rasch 1991; Chu, Strand, and Fjelland 2003; Alhadeff-Jones 2008; Morrison 2010), considering the 'range of different theories that deal with the implications related to the notion of complexity' (Alhadeff-Jones 2008, 66). The growth in special CAS research groups, journals and books is so profuse (Allen, Maguire, and McKelvey 2011; Byrne and Callaghan 2014) that one might be led to think that it is possible to speak of a 'complexity turn' (Urry 2005) that is informing new ways of doing science and understanding the nature of real-world problems. Often the term 'complexity science' is used interchangeably with 'complexity theory', 'complex adaptive systems' or even just 'complexity'.

The French complex systems philosopher, Edgar Morin (2008), suggests that one possible definition of complexity could be found by looking at the Latin roots of the word 'complex'. The first meaning of the word 'complexity' comes from the Latin word complexus, which means 'what is woven together' (Morin 2008). It seems that even in its original form, the notion of complexity tells us that we should not expect a neatly packaged explanation of where it came from and how it came about. The development of a theory of complexity can consequently be described as a 'weaving together' of discoveries made in different scientific disciplines over a period of time and encompasses a collection of concerns and methods recognisable as an entity (Checkland 1993). In his construction of 'a geography of complexity theory', Thrift $(1999,33)$ describes 'complexity theory' as being a 'scientific amalgam ..., an accretion of ideas, a rhetorical hybrid' that has not developed from one point of diffusion. As a result, a standard account of the development of a 'theory of complexity' is not available. Even so, there are attempts to chronologically trace the developments and possible origins of this paradigm of thought; indeed, there are several such accounts (Waldrop 1993; Heylighen 1997; Rescher 1998; Rasch and Wolfe 2000; Meyers 2009; Ramage and Shipp 2009; Castellani 2018).

Although there is no 'grand theory of complexity', one can recognise a certain 'economy of concepts' (Thrift 1999) that arranges itself around the characteristics of CAS (see Section 'The features and behaviour of CAS'). Checkland (1993) suggests that it might be better to think of all the endeavours that have notions of complexity and the study of complex phenomena as their main purpose as processes that embrace a 'complexity approach' rather than trying to unite these efforts in a 'grand theory' of complexity. Similarly, Cilliers $(2007,4)$ suggests that it might be more effective to deal with complexity by adopting a 'complexity attitude':

Once we realize that we are dealing with complex things, and we accept the consequences of this, our approach to what we are doing, irrespective of how we are actually doing it, will change fundamentally.

Checkland's notion of a 'complexity approach' and Cilliers's suggestion of a 'complexity attitude' can be linked to what Morin (2008) calls a 'paradigm of complexity' or what others call 'complexity thinking' (Rogers et al. 2013). Morin's use of the term 'paradigm' is based on Thomas Kuhn's definition: Kuhn (1996) defined 'paradigm' as an overarching collection of 
beliefs and assumptions that result in the organisation of scientific worldviews and practices. Foucault's notion of episteme is also related to the notion of paradigm. Instead of trying to conceptualise a general theory of CAS, the notions of 'approach', 'attitude' and 'paradigm' turn the focus of inquiry around in a radical way. These concepts allow one to expand the idea(l) of complexity to the extent that it becomes 'capable of informing all theories, whatever their field of application or the phenomenon in question' (Morin 1992) might be. Formulating a complexity approach, attitude or paradigm thus allows one to look outwards and alongside other discourses. From this meta-position, the notion of complexity arranges itself in such a way that it does not stay passively outside or alongside other discourses, but actively and dynamically infects and disseminates them. For the purpose of this book, we will rather use the word 'worldview' instead of 'paradigm' so as not to get caught up in technical discussions about when a new way of thinking qualifies as being a new paradigm (or not).

\section{Worldviews and how they shape scientific research and our understanding of the world}

A worldview contains ideas about how the world and the universe came about, and expresses what we believe to be real, how we can study these phenomena, and how this informs our values and judgements in deciding how we should act in the world (Dilthey 1954). In the field of philosophy of science, we would say that when we are enquiring into the nature of knowing which phenomena are real or not, we are dealing with the fundamental philosophical questions of ontology and epistemology. Ontology refers to questions and assumptions that relate to understanding what the nature of reality is (i.e. what exists?). Epistemology concerns itself with questions about how we do or can know what exists (i.e. theories and how to gain knowledge about reality) (Hammond 2005; Rousseau 2017).

In many different scholarly publications on CAS, the study of complexity is often posed as an alternative to the classical scientific or Newtonian worldview. Many scholars pose the acknowledgement of complexity as a shift in worldview (Capra 2005; Mazzocchi 2008; Wells 2013; Boulton, Allen, and Bowman 2015) and frame it as an inquiry into the nature of reality that opens up an alternative approach from the one used by Enlightenment scientists (also known as 'Newtonian thinking' or 'Newtonian science') to ground the basic assumptions of traditional scientific inquiry. To understand what this shift means, it is important to understand the significance of the Newtonian worldview, and the assumptions that inform the modern scientific method. We will first explain this in more detail before we discuss the assumptions that inform a CAS-based worldview.

\section{A short introduction to the Newtonian worldview}

The modern Enlightenment or Newtonian worldview is based on insights from 16th- and 17th-century European scholars, and the discoveries they made that informed what is called 'the Scientific Revolution', which includes the 'Copernican Revolution' (Toulmin 2001). Advances in telescopes allowed scholars to observe that the Sun is the centre of the universe (heliocentrism) and it replaced the theory developed many centuries earlier by the Egyptian philosopher Ptolemy, who posed that the Earth was the centre of the universe (geocentrism) (Merchant 1989). These findings, together with the discovery of Newton's laws of physics (Newton 1686), formed the birth of 'modern science', which stated that empirically based knowledge that is universally applicable could be used to study the nature of phenomena in the world. 
The Scientific Revolution is considered to be a central episode in the history of science, the historical moment at which the unique way of understanding the world that we call 'modern science' and its institutions emerged (Toulmin 2001). Ever since then, classical mechanics were regarded as the foundation of scientific inquiry and formed the conceptual model of the physical world (Mazzocchi 2008). The metaphor of the Earth or nature being constituted in a mechanical manner informed what philosophers of science call the 'mechanistic view of nature' (Merchant 1989, 2018), positing that all natural phenomena behave in ways that are determined by physical mechanisms (such as the laws of gravity and the laws of motion). This view informed an understanding of the natural world as being in equilibrium (stable and steady), orderly, deterministic and predictable in which the parts of matter, like the parts of machines, were well defined, passive and inert (Arthur 2015).

By claiming that only phenomena that can be observed and quantified can be justified to exist, the Newtonian worldview supports a reductionist ontology which assumes that phenomena are empirically verifiable by dividing them into elementary parts (such as atoms and electrons) that can be studied and observed by means of isolation or analysis (by separating the parts from the whole and by cutting the whole up into its smallest parts). Often the dictum 'the whole is equal to the sum of its parts' is used to qualify a reductionist ontology and implies that all properties of an object can be explained through the individual behaviour of its smallest constituent parts.

The Newtonian method assumes that knowledge can only be considered scientific if the processes of observing, experimenting with and measuring phenomena are based on the conditions of independent verifiability and reproducibility (Joel 1983). Related to these conditions are the principles of empirical verification and deductive reasoning, which establish strict conditions under which a theory can be proven to be true. These principles and conditions underpin the possibility of gaining objective knowledge about phenomena. Objective knowledge is defined as universally verifiable knowledge that is not influenced by contextual variables or subjective interpretations of observations or measurements.

Based on this reductionist ontology and objective epistemology, the Newtonian worldview produced a scientific basis on which to formulate universal knowledge about phenomena that were seen to behave in a deterministic and predictable manner. This allowed scholars to express universal laws and make predictions of how phenomena would behave once initial conditions were known, based on the assumption that the behaviour of the system could be described in terms of linear equations. This ability gave the Newtonian worldview a significant advantage over other worldviews, as it provided the conceptual and methodological tools to justify and verify the truth about what is real. Combined with the advantage of being able to make predictions about behavioural outcomes of material phenomena, the Newtonian worldview provided a means to inform policies, social processes and institutions that favoured and supported the mechanisation, industrialisation, standardisation and formalisation of processes of production and modes of organising societal norms (Toulmin 2001).

The postulates and principles of the Newtonian scientific worldview that were founded in the natural sciences through physics and mathematics formed such a coherent framework for explaining mechanistic and physical phenomena in equilibrium that its assumptions were soon transferred to other fields of study such as the social sciences to revise and reconstruct theories for guiding our understanding of the human condition. In the discipline of economics, for example, the Newtonian worldview inspired theories that viewed the economy as a well-ordered system in equilibrium in which agents are all identical and rational and make independent decisions by analysing trade-offs between personal cost and benefits in order to determine whether the action is worth pursuing for the best possible outcome (Arrow 1968; 
Arthur 2015). In the discipline of sociology, Newtonian principles were embraced to inform modernist theoretical positions such as Structuralism. Structuralism provided ontological and methodological foundations that allowed social scientists to uncover and define the abstract structures that underlie all the things that humans do, think, perceive and feel (Blackburn 2008). Structuralism rose to prominence in France in the 1960s and formed a movement that offered a single unified approach to human life that would embrace a wide range of disciplines such as linguistics (De Saussure 1974), psychoanalysis (Lacan 2006), psychology (Piaget 1985), literary theory (structural semiotics) and anthropology (Lévi-Strauss 1963). In the discipline of philosophy, the tradition of analytic philosophy adopted the principles of formal logic and mathematics to establish principles for formulating conceptual clarity and rigour in arguments through the use of language (Tarski 1959). Central figures in this historical development of analytic philosophy were Gottlob Frege (1980), Bertrand Russel (1945), Ludwig Wittgenstein (1953), Saul Kripke (1972) and Karl Popper (1972).

\section{The breakdown of the mechanistic worldview}

Although the Newtonian worldview serves as the basis of the modern scientific approach, new discoveries in the field of quantum physics and relativity theory after the 1950s provided significant results that showed that the Newtonian principles were only valid when applied to well-defined problems and explained the behaviour of matter only under certain stable conditions. The breakdown of the mechanistic, unified and stable worldview was further shattered by the inadequacy of the Newtonian paradigm to formalise the behaviour and fundamental nature of quantum particles. In addition, the work of Russian physicist, Ilya Prigogine (1996), revealed that the 'clock-like machine model of nature and society that dominated the better part of three centuries of western thought' (Merchant 2018) broke down when questions were asked about the nature of phenomena on the subatomic level or under conditions of very high or very low temperatures. Prigogine received the Nobel Prize for his study of open systems and argued that classical thermodynamics holds only for systems that are in equilibrium or near equilibrium, such as pendulum clocks, steam engines and solar systems (Prigogine 1996). These are stable systems in which small changes in the system lead to adjustments and adaptations. They are described mathematically by the great Enlightenment scholars who used calculus and linear equations.

But what happens when the input is so large that the system cannot adjust? In these far-from-equilibrium systems, non-linear dynamics take over. In these cases, small inputs can produce new and unexpected effects (Merchant 2018), as we have seen in the COVID-19 global pandemic where it is now assumed that a virus jumped from an infected wild animal to humans, with massive global economic and social consequences. These new discoveries in the physical sciences led to the emergence of a new ontology, and coincided with discoveries that were being made in other scientific fields such as biology, ecology, cybernetics and artificial intelligence. Insights from research in ecology illustrated that, by departing from a mechanistic worldview, the notion of life and living organisms was better understood in terms of a 'systems view of live' (Capra and Luisi 2014). This introduced a new way of thinking, and offered new perceptions, a new language and new concepts for describing the processes and features of living organisms that could also be applied to social phenomena. The birth of general systems theory is often ascribed to the work of the biologist Ludwig von Bertalanffy (1968), who formulated a general theory of systems that could explain the behaviour of all living systems. He was interested in finding those principles that are common 
or general to all organisms to provide the conceptual language for an 'organismic' science. As he observed,

there exist models, principles, and laws that apply to generalized systems or their subclasses, irrespective of their particular kind, the nature of their component elements, and the relationships or "forces" between them. It seems legitimate to ask for a theory, not of systems of a more or less special kind, but of universal principles applying to systems in general.

(Von Bertalanffy 1968, 32)

In his critique of the mechanistic and reductionist metaphysics of science, Ulanowicz (2009) proposes 'a conversion of mind' concerning the Newtonian paradigm. With his focus on the notion of 'ecology', he suggests that we need a scientific worldview that departs from being 'wholly dependent on physics and chemistry for its explanations'. Building on the work of Gregory Bateson (1972), Ulanowicz (2009) argues that it is crucial to find complementary narratives for the same phenomena in order to accommodate the characteristics of complex and adaptive ecological dynamics. These differences can be used to develop a logical and coherent perception of ecological phenomena in general and to understand the idea of life specifically. Looking through 'Newtonian glasses' (Ulanowicz 2009) does not give the full picture.

What is of importance in tracing the roots of CAS understanding is not the scientific and historical details of these changes, but the fact that a shift took place in the way in which natural scientists and subsequently social scientists and other applied fields of study thought about our relationship to the world and about humankind's status in the world. This rupture in the classical scientific view of the relationship between our descriptions of the world (epistemology) and the nature of what is real (ontology) opened up a new space in which new concepts and theories could take shape and develop. The seed of what is now known as 'the complexity approach' took root in this space, eventually finding its way into informing the pioneering ideas of SES research.

\section{A relational worldview of CAS}

A CAS worldview suggests that systems are constituted not only by parts and mechanical kinds of interactions, but that they come about as the result of relations and organisational processes that constitute matter and its interactions. The discoveries in the fields of general systems theory, cybernetics, studies of neural networks, biology and ecology during the 1950s pointed to the fact that not all matter behaves in the same way as planets, deterministic machines or atoms. Living systems, in particular, come about and behave in ways that are the result of underlying emergent and complex sets of causal relations and organisational patterns (Von Foerster 1960; Von Bertalanffy 1968; Bateson 1972; Kauffman 1993; Gell-Mann 1994; Meadows 2008; Capra and Luisi 2014). By drawing on these discoveries, it became clear that the essential properties of living systems are properties of the whole, which none of the constituent parts has. The immune system is a good example of this: we cannot extract it from the body or analyse it under a microscope, because it does not exist in one particular organ, but is a systemic property of the interactions of various organs, processes and body functions.

In her definition of a system, Meadows (2008) argues that a system can be described as 'a set of things - people, cells, molecules, or whatever - interconnected in such a way that they produce their own pattern of behaviour over time'. This basic and succinct description of a 
system suggests that systemic properties emerge through the dynamic interaction between interconnected elements that cause systems to produce their own patterns of behaviour over time. The interlinked parts of systems produce emergent effects that are different from the combination of effects of each part on their own. In this understanding we see that relations and the emergent causal organisational interactions are acknowledged to have real effects on a systemic level of the whole, and we can therefore say that the relations are ontological (i.e. something real). This view contrasts fundamentally with the Newtonian worldview, which excludes unobservable, immeasurable relations and organisational patterns as having any ontological status.

A CAS-based worldview therefore offers an alternative to the Newtonian ontology, and entails a shift or move beyond viewing the world in a mechanistic sense (Ulanowicz 1999, 2007). When dealing with CAS, the limitations of the grounding principles of the Newtonian worldview are revealed. A CAS approach provides an expanded worldview with assumptions that are more attuned to the nature of living systems. As argued by many CAS scholars, this worldview is based on understanding that the nature of reality is not mechanistic but organic, and allows us to see the world as being made up of interconnected dynamic relations and interactions that are generative and adaptive, unorderly, unpredictable and full of surprises (Wells 2013; Arthur 2015; Merchant 2018). Research in various fields has shown that even when the underlying rules or interactions that constitute a system are extremely simple, the behaviour of the system as a whole can be rich and complex (Cilliers 1998). The processes of organisation in complex systems are not compressible or reversible (Wolfram 2002). Emergent properties (such as life, consciousness, climate) arise from the interactions and relations between the constitutive parts and are destroyed when the system is dissected or isolated. A CAS-based worldview allows us to regard such non-material causes, relations and organisational patterns as being real and regard the emergent nature of phenomena as essential systemic properties.

This kind of worldview is known in philosophy as a process-relational worldview and has been discussed since the pre-Socratics. Heraclitus, for example, is credited with the famous expression 'everything flows'. A process-relational worldview provides conceptual constructs that highlight connections and relational qualities, and focuses attention on processes and relations, as opposed to objects, as the primary constituents of reality (Hertz, Mancilla García, and Schlüter 2020; Mancilla García et al. 2020). Processes can be understood as patterned change over time, and their properties and functions are defined by the set of relations that constitute them. These relations span different fields of study and integrate the social and the ecological, which is why a process-relational worldview is particularly useful for conceptualising SES and integrating CAS theories into the study of SES (Rogers et al. 2013).

\section{Social-ecological intertwinedness}

A particular feature that distinguishes SES from other CAS, such as financial systems or ecosystems, is their social-ecological intertwinedness. The notion of intertwinedness captures the co-constitutive nature of social and ecological relationships. Drawing attention to this intertwinedness is necessary to safeguard against reductionist tendencies that treat the social and the ecological as separate realms that exist, and can be studied and understood, independently from each other. Instead, the concept of social-ecological intertwinedness emphasises that SES are co-constituted in ways where one cannot understand the social aspects without making reference to the ecological, and vice versa. Put differently, the conceptualisation of SES as intertwined systems views entities, agency and other SES outcomes as 
coming into existence through the interaction of social and ecological processes to the extent that it is impossible - and rarely useful - to separate the two.

Intertwinedness is driven by concrete processes in space and time, such as processes of co-adaptation and coevolution. Lansing and Kremer's (1993) account of the emergence of the highly complex crop management system on the island of Bali, for example, is seen as a process of co-adaptation involving farmers, crops, pests, cultural practices and the physical geography of Bali. What these individual components are (and why they do what they do in bringing the emergent phenomena about) is defined by - and can only be understood with reference to - the very process of co-adaptation.

\section{The features and behaviour of CAS}

Complex adaptive systems have certain distinguishable properties (features) and behaviours (dynamics) that invite us to explore and discover new ways of studying and governing systems such as SES. Preiser et al. (2018) developed a set of six general organising principles that can be used to qualify and define the way in which complex phenomena present themselves in the world. The six principles present a typology of characteristics that allows us to discern the qualities of CAS and offer suggestions on the practical implications of CAS-based approaches for assessing and applying appropriate methods to study, understand and govern CAS. These principles are:

1. Constituted relationally: Complex adaptive systems are constituted relationally, which means that complex behaviour and structures emerge as a result of the recursive and aggregate patterns of relations that exist between the component parts of systems. These relations usually give rise to rich interactions within the system, meaning that any element in the system influences and is influenced by many other ones (Cilliers 1998) either directly, or indirectly via positive (reinforcing) or negative (balancing) feedbacks.

2. Adaptive: Complex adaptive systems have adaptive capacities and self-organise and coevolve in relation to contextual changes. Self-organisation describes the process whereby a system can develop complex structures from fairly unstructured beginnings without the intervention of an external designer or the presence of some centralised form of internal control (Ashby 1947). Coevolution describes the recursive patterns or relations of influence that result from ongoing exchanges between components of evolving systems, practices, knowledge, beliefs and values, and the biophysical environment that mutually influence one another (Norgaard 1994; Haider et al. 2020).

3. Dynamic: Complex adaptive systems are characterised by dynamic relations. In other words, the relationships in a system are constantly changing in rich and unexpected ways. These relations are mostly non-linear, which means the relationships between any two factors or processes are not necessarily uniform or proportional (Boulton, Allen, and Bowman 2015). Non-linearity can be the result of feedbacks, path dependencies, time lags or multiple time scales, which suppress or magnify processes and interactions, both internally and between the system and its environment. In CAS, non-linear dynamics also arise because the relations between variables constantly change, which renders them uncertain and unpredictable and makes these systems difficult to control (Arthur 1999). Change and not stability is thus the norm in CAS, shifting the focus from analysing stable states to analysing transient processes (the behaviour of the system in between equilibria), and from analysing outcomes to focusing on the trajectories or processes of the system. 
4. Radically open: Complex adaptive systems are radically open. In other words, it is the activity of the system in relation to the environment that constitutes the system itself (Cilliers 2002). This implies that we cannot clearly discern the boundary between the system and its environment, because the environment co-constitutes the identity of the system. Our definitions of systemic boundaries are thus the product of physical properties (e.g. a watershed boundary that signals a system boundary), mental constructions (i.e. where we choose to draw the line between the system and the environment (Ulrich 2000; Rajagopalan and Midgley 2015)) or the problem or research question we want to address (including the temporal and spatial scales of interest).

5. Contextual: Complex adaptive systems are context dependent, meaning that the function(s) of CAS are contingent on context. Changing the context will have an impact on the function of the system. In other words, the environment suppresses or enhances possible systemic functions (Poli 2013). Moreover, the functions that we ascribe to complex systems are contingent on the level of analysis that we employ to understand a system.

6. Complex causality and emergence: Complex adaptive systems are characterised by complex causality and emergence. Cause-and-effect interactions in CAS are not unidirectional or linear, but marked by complex recursive causal pathways that are non-linear and dynamic (Rasch and Knodt 1994). Emergence occurs when entities are observed to have systemic properties that are different and non-reducible to the properties of the constituent elements. It is not that the sum is greater than the parts, but rather that the system's effects are different from those of its parts (Urry 2005). Emergent phenomena have causal agency and are real, i.e. they have ontological status (Kauffman 2008).

Table 2.1 summarises the conceptual and practical implications of these features for studying and intervening in SES. The challenge of being able to understand CAS, and the difficulties it poses for research are among the distinguishing characteristics of CAS-based approaches to sustainability (Allen 2001; Bammer et al. 2020). Addressing intertwined, complex sustainability challenges in SES requires expertise in integrating research, and practice to develop a more holistic and comprehensive understanding of the nature of these challenges and to embrace the 'messiness' of working with them (Duit and Galaz 2008; Rogers et al. 2013; Arthur 2015; Boulton, Allen, and Bowman 2015). The implications of these issues for the practical implementation and design of SES research are further discussed in Chapter 3.

\section{Implications of a CAS worldview for doing SES research}

Understanding the nature of SES as complex adaptive systems poses new frontiers for studying, governing and influencing SES (Biggs, Schlüter, and Schoon 2015; Bodin 2017; Österblom et al. 2017). Understanding SES as complex adaptive systems has profound implications for our assumptions about what kind of knowledge we can have of SES (ontological implications), how we gain knowledge of SES (epistemological implications) and how we judge whether we have conducted our research in 'good' and just ways (ethical implications).

As discussed earlier in this chapter, many different disciplines have influenced the development of a range of 'theories of complexity'. As a consequence, there also exists a diversity of methods for doing research on CAS (Preiser 2019). Some methods aim to quantify and simulate the behaviour, connections, structures and phases of complex systems by means of mathematical equations, algorithms and computational models (Thurner, Hanel, and Klimek 2018). Other approaches extend the vocabulary of computational complexity to a qualitative engagement with the features of complexity (Audouin et al. 2013). 
Table 2.1 General organising principles of complex adaptive systems (CAS), and implications for SES research approaches and methods

\begin{tabular}{|c|c|c|}
\hline $\begin{array}{l}\text { Organising } \\
\text { principles of CAS }\end{array}$ & Conceptual implications for SES research & Practical guidelines for SES research \\
\hline $\begin{array}{l}\text { Constituted } \\
\text { relationally }\end{array}$ & $\begin{array}{l}\text { The nature and structure of } \\
\text { relationships in an SES have to be } \\
\text { considered explicitly. } \\
\text { Diversity is key and allows for } \\
\text { different kinds of SES interactions to } \\
\text { take place. }\end{array}$ & $\begin{array}{l}\text { - Assess the nature of relations } \\
\text { and structures of networks and } \\
\text { connectivities } \\
\text { - Foster trust, dialogue, distributed } \\
\text { accountability and collaboration } \\
\text { across a variety of networks and levels } \\
\text { of organisation } \\
\text { - Create integrative frameworks and } \\
\text { methods to assess relations and } \\
\text { connectivity } \\
\text { - Actively recognise diversity as a } \\
\text { resource in the system } \\
\text { Create transformative spaces where } \\
\text { people can learn and foster the } \\
\text { experience of being connected to } \\
\text { one another and nature in deep and } \\
\text { meaningful ways }\end{array}$ \\
\hline Adaptive & $\begin{array}{l}\text { The function and structure of SES } \\
\text { change with temporal and spatial } \\
\text { changes. } \\
\text { - Multiple modes of reorganisation } \\
\text { are possible when systems undergo } \\
\text { change. } \\
\text { - Adaptive capacity results from a } \\
\text { system's ability to learn and have } \\
\text { memory. } \\
\text { - Change happens through } \\
\text { adaptation, evolution and } \\
\text { transformation. } \\
\text { - Control is not located in one isolated } \\
\text { element of the system, but is spread } \\
\text { throughout the nodes and relations } \\
\text { of the system. }\end{array}$ & $\begin{array}{l}\text { - Critically reflect on planning and } \\
\text { strategy design and implement } \\
\text { adaptive co-management } \\
\text { practices to foster iterative learning } \\
\text { and collaborative processes of } \\
\text { engagement } \\
\text { - Facilitate continuous innovation } \\
\text { based on experiential learning across } \\
\text { several iterations of trial and error } \\
\text { - Support capacities that allow for self- } \\
\text { organising processes } \\
\text { - Develop holistic frameworks that } \\
\text { cultivate synthesis rather than analysis } \\
\text { - Assess resilience and anticipate } \\
\text { possible future patterns and pathways }\end{array}$ \\
\hline Dynamic & $\begin{array}{l}\text { - System behaviour is amplified or } \\
\text { dampened by feedback loops, and } \\
\text { can lead to tipping points and } \\
\text { regime shifts. } \\
\text { - Feedback structures are responsible } \\
\text { for the changes we experience over } \\
\text { time. } \\
\text { - Structures and processes are linked } \\
\text { across scales. } \\
\text { - SES are characterised by inherent } \\
\text { unpredictability and uncertainty. }\end{array}$ & $\begin{array}{l}\text { - Map systemic feedbacks across } \\
\text { different spatial and temporal scales } \\
\text { - Assess which mechanisms build or } \\
\text { inhibit systemic agency and resilience } \\
\text { - Identify systemic thresholds, traps } \\
\text { and indicators that could help detect } \\
\text { possible regime shifts } \\
\text { - Capture spatial and temporal cross- } \\
\text { scale dynamics } \\
\text { - Investigate thresholds and tipping } \\
\text { points }\end{array}$ \\
\hline
\end{tabular}

(Continued) 
Rika Preiser et al.

Organising

principles of CAS Conceptual implications for SES research Practical guidelines for SES research

Radically open - Delimiting SES problems and systems - Treat projects and geographical is challenging as real-world problems locations as if they are not closed and have no natural boundaries. isolated entities

- External variables could have important influences on system

- Be aware that unknown variables behaviour but cannot be included in could have important influences on the models of the system.

- Any modelled system is embedded in a larger system. system behaviour and expect these to have real effects on the system under study

- Assess teleconnections and the effects of the flow of energy, matter and information to demonstrate how systems are embedded in other systems

\begin{tabular}{|c|c|c|}
\hline Contextual & $\begin{array}{l}\text { - SES are context sensitive. } \\
\text { - SES components have multiple } \\
\text { functions that change when the } \\
\text { context changes. } \\
\text { - Context is not a passive backdrop } \\
\text { to a system, but an active agent } \\
\text { in itself, which enables or inhibits } \\
\text { systemic agency. } \\
\text { - Many contested problem definitions } \\
\text { exist simultaneously and the various } \\
\text { stakeholders involved in an SES } \\
\text { will have different mental models } \\
\text { or beliefs that inform values and } \\
\text { understandings of both the causes } \\
\text { and the possible actions that could } \\
\text { be taken to find possible pathways } \\
\text { for action. }\end{array}$ & $\begin{array}{l}\text { Foster iterative processes of meaning- } \\
\text { making that facilitate dialogue to } \\
\text { include multiple perspectives from a } \\
\text { wide range of stakeholders } \\
\text { - Use multiple evidence-based data } \\
\text { sources to co-create and integrate } \\
\text { different knowledge bases } \\
\text { - Develop context-dependent } \\
\text { assessments and systemic } \\
\text { understanding of challenges }\end{array}$ \\
\hline $\begin{array}{l}\text { Complex } \\
\text { causality and } \\
\text { emergence }\end{array}$ & $\begin{array}{l}\text { - Cause-and-effect cannot be traced } \\
\text { in linear causal trajectories. } \\
\text { - Emergent phenomena arise from } \\
\text { multiple recursive patterns and } \\
\text { unintended outcomes. }\end{array}$ & $\begin{array}{l}\text { - Engage methods that can } \\
\text { illuminate emergence and } \\
\text { unexpected outcomes } \\
\text { - Adopt a complexity-based frame } \\
\text { of mind in considering innovative } \\
\text { practices and new decision } \\
\text { possibilities } \\
\text { - Expect uncertainty and surprises } \\
\text { to be part of any engagement } \\
\text { with complex SES } \\
\text { - Anticipate alternative future } \\
\text { pathways and innovations } \\
\text { through experimental processes } \\
\text { such as scenarios and foresight } \\
\text { methods }\end{array}$ \\
\hline
\end{tabular}

Source: Adapted from Preiser et al. 2018. 
Within the field of SES research, researchers use field research (e.g. Hahn et al. 2006; Gelcich et al. 2010; Herrfahrdt-Pähle et al. 2020), network approaches (e.g. Bodin et al. 2019), and mathematical and computational modelling (Schlüter and Pahl-Wostl 2007; Lade et al. 2017; Martin, Schlüter, and Blenckner 2020), as well as combinations thereof, to shed light on the behaviour of SES, often in exploratory ways. Several methods and tools (like dynamic modelling) are used to explore the different ways an SES may unfold in different contexts (e.g. Lade et al. 2017) and to enhance understanding of key processes and CAS properties such as self-organisation or emergence from local interactions, feedbacks, stochasticity and intertwinedness (Lindkvist, Basurto, and Schlüter 2017; Orach, Duit, and Schlüter 2020). In Chapter 33 we provide a synthesis of the current landscape of SES research methods and their ability to study and account for various CAS features. In the next sections, we discuss the ontological, epistemological and ethical implications of CAS-based approaches to SES research.

\section{Ontological implications: complexity is a real feature of systemic interactions}

From a CAS-based worldview, complexity emerges as a real property of systems that exhibit the six principles discussed in the previous section. A CAS-based worldview suggests that reality is constituted by the 'complex interaction between dynamic, open, stratified systems, where particular structures give rise to certain causal powers, tendencies or ways of acting' (Mingers 2000, 1261-1262). Complex adaptive systems therefore do not exist independently from the phenomena and processes that constitute them (Gell-Mann 1994; Holland 1995; Cilliers 1998). As an outcome of dynamic relations and processes, complexity is thus simultaneously a combination of the attributes of the system (ontological) and a function of our present understanding of that system (epistemological) (Cilliers 2008).

This implies that there is no objective position from which to study complex phenomena, as knowledge of CAS is always context sensitive. This knowledge is best generated through methods that seek to understand the bigger picture (holistic) of how certain patterns of behaviour are linked to various contexts, histories and different variables, and how they change over time. This implies that gathering data or information about CAS is often best achieved by methods and research approaches that allow us to record and track the changing nature of phenomena over temporal and spatial scales, and that allow us to see how systems adapt and respond to dynamic interactions such as feedbacks and tipping points. It also suggests that we cannot generate universal objective knowledge about CAS, but have to allow ourselves to delve into the process of observing adaptation, change, diversity and emergent behaviour.

A relational worldview is well supported by the broader theoretical position as upheld in the ideas of critical realism (Mingers 2006). Critical realism is a branch of philosophy that distinguishes between the 'real' world and the 'observable' world. It suggests that although the 'real' (that which exists) cannot be observed, it ultimately exists independently from human perceptions, theories and constructions. Just because we cannot observe it, it does not mean that we should dismiss it (which would revert to a constructivist form of realism).

Critical realism theory can be applied to social sciences as well as natural sciences, and generally informs an understanding of knowledge generation that is grounded in the notion that unobservable events can cause observable events, structures and processes. Values and beliefs about the importance of some natural phenomena or events cannot be observed, for example, but they influence the policies and social norms that inform whether those phenomena are worthy of protection or conservation, or not. A CAS-based worldview does not 
imply that 'everything goes' nor that we should disregard the validity of certain kinds of knowledge systems. In fact, it rather invites us to consider multiple causes that can interact in seen and unseen ways to influence systems in ways that are unpredictable and not always quantifiable, but have significant influences on CAS dynamics across temporal and spatial scales.

\section{Epistemological implications: embrace methodological pluralism for studying CAS}

Complex adaptive systems-based research approaches introduce a different way of thinking about the world and how to understand our place in it. Although it does not provide us with a foolproof, best-practice manual for how to design research projects or change interventions (Preiser and Cilliers 2010), it does provide some general premises that may reduce the tendency to oversimplify reality or analyse systems in ways that generate misleading conclusions. To produce empirically valid and meaningful data and interpretations of the diversity of features and properties of SES, we need to expose and understand the underlying causal relationships, patterns and processes that generate systemic behaviour, patterns and events that govern anthropogenic and non-anthropogenic drivers and social-ecological conditions (Capra 2005; Österblom et al. 2013). Deciding which methods and models are appropriate for a particular purpose and research aim is not obvious, and choices are often made on subjective grounds such as experience, usefulness or even intuition (Mingers 2000; Audouin et al. 2013; Cilliers et al. 2013). This means we often take pragmatic research approaches.

Knowledge of CAS is always partial and our knowledge of certain phenomena can change over time as we gain deeper insight into the features and effects of certain systemic behaviour. Therefore, the best strategy for developing an integrated understanding of SES is to explore a variety of models and frameworks that span a broad spectrum of methodologies and disciplinary divides (Cilliers 2002; Poli 2013; Tengö et al. 2014). A CAS-based epistemology comprises a range of scientific theories and frameworks (Chapman 2016) that can describe, assess and confirm the complex features and dynamics of CAS. By combining different strategies and methods of collecting and interpreting knowledge, insights from different perspectives can be enriched and integrated, and help to contextualise the knowledge claims made by different disciplines (Morin 2008; Bammer et al. 2020). Ulrich $(1994,35)$ suggests that 'from this new perspective, the implication of the systems idea is not that we must understand the whole system, but rather that we critically deal with the fact that we never do'.

A CAS-based worldview therefore emphasises the benefits and need for methods of inquiry and knowledge-generating practices that draw from a plurality of relevant epistemologies and frameworks (Mitchell 2004; Moon and Blackman 2014; Tengö et al. 2014; Reyers et al. 2015). Engagement with different knowledge types and forms needs to occur in ways that facilitate interactions among researchers from different disciplinary backgrounds (Berkes, Colding, and Folke 2003; Burns and Weaver 2008; Audouin et al. 2013; Klein 2016; Schlüter et al. 2019b) as well as among researchers and stakeholders who should be involved in the research process (Cockburn et al. 2020). Practising methodological pluralism (Norgaard 1994) and epistemological agility (Haider et al. 2018) can therefore be considered as key competencies in SES research. The epistemological limitations of what we can know imply a need for a critical attitude towards tackling problems and issues of decision-making, and provide us with an ethical basis for developing tools of critical reflection. 


\section{Ethical implications: actions and decisions can never be made without considering the intertwined nature of complex SES}

Complex adaptive systems-based approaches highlight the need for critical reflexivity to align ontological, epistemological and methodological commitments. Social-ecological research is often driven by solutions-oriented and use-inspired outcomes (Clark 2007). In the quest for being pragmatic, a common problem in this kind of 'solutions-oriented' research can be to use readily available approaches and methods that poorly account for CAS assumptions. The use of such methods risks imposing a particular understanding of reality on the research, and closing down other understandings that may allow novel insights and practical approaches to effecting change to emerge. At the same time, it is critical to recognise that choices have to be made; a normative element is therefore always present in our attempts to understand the complex intertwinedness of SES. The normative dimension of our knowledge of CAS means that engagement is needed, not only in generating an understanding of the system itself but also in choosing - and making explicit - the context/framework by which that knowledge is generated. These interrelated tasks typically call for a transdisciplinary approach that includes empirical, pragmatic and normative or value-based knowledge (Max-Neef 2005; Burns, Audouin, and Weaver 2006).

In navigating research, action and decision-making processes in the Anthropocene, the relational interdependencies of SES should always be acknowledged. Complex adaptive systems-based approaches suggest a need to proceed differently and call for more inclusive and integrative modes of engaging with real-world SES problems that acknowledge the intertwinedness of humans and nature, the limits of what is knowable and how we can act to effect change in complex SES. Complex adaptive systems-based approaches call for participatory and collaborative multi-stakeholder processes that foster dialogue and knowledge co-creation, and the development of more systemic awareness (Hammond 2005). In particular, they call for research informed by broader societal framings and understandings of problems, novel forms of collaborative agency with various actors in a system and alternative moral constructs (Woermann 2016). Finally, they imply the need to actively favour the integration of nature, society and technology in policy design and implementation.

\section{Conclusion}

This chapter provided insight into the philosophical and conceptual underpinnings of SES research. Knowing that the nature of reality is complex has profound consequences for how we go about understanding and acting in real-world, intertwined SES. A complexity-based understanding of the nature of reality has emerged through insights and influences from a wide variety of different disciplines, and has arisen as an alternative to the Newtonian worldview that has dominated modern science. This shift in our assumptions about the nature of the world, from a mechanistic cause-and-effect understanding to a much more organic understanding with complex causation, has deep consequences for the ways in which we go about doing SES research, our assumptions about what we can know, and how we can act on that knowledge to effect change and address real-world sustainability challenges. The next chapter builds on this understanding to discuss the practical design and execution of SES research.

\section{Acknowledgements}

Rika Preiser's salary was co-funded by the Swedish International Development Agency's (Sida) GRAID and Swedbio programmes. Maja Schlüter received funding from the 
European Research Council under the European Union's Horizon 2020 research and innovation programme (grant agreement no. 682472 - MUSES). Reinette Biggs received support from the South African Research Chairs Initiative (SARChI) (grant 98766), the GRAID project and a Young Researchers Grant from the Vetenskapsrådet in Sweden (grant 621-2014-5137).

\section{References}

Alhadeff-Jones, M. 2008. 'Three Generations of Complexity Theories: Nuances and Ambiguities.' Educational Philosophy and Theory 40(1): 66-82.

Allen, P. 2001. 'What is Complexity Science? Knowledge of the Limits to Knowledge.' Emergence 3(1): $24-42$.

Allen, P., S. Maguire, and B. McKelvey, eds. 2011. The Sage Handbook of Complexity and Management. London: Sage.

Arrow, K. 1968. 'Economic Equilibrium.' In International Encyclopedia of the Social Sciences, edited by R.K. Merton and D.L. Sills, 376-389. New York: Macmillan.

Arthur, W.B. 1999. 'Complexity and the Economy.' Science 284: 107-110. doi:10.1126/science.284. 5411.107.

Arthur, W.B. 2015. Complexity and the Economy. Oxford: Oxford University Press.

Ashby, W.R. 1947. 'Principles of the Self-organizing Dynamic System.' Journal of General Psychology 37: $125-128$.

Audouin, M., R. Preiser, S. Nienaber, L. Downsborough, J. Lanz, and S. Mavengahama. 2013. 'Exploring the Implications of Critical Complexity for the Study of Social-Ecological Systems.' Ecology and Society 18(3): 12. doi:10.5751/ES-05434-180312.

Bammer, G., M. O’Rourke, D. O'Connell, L. Neuhauser, G. Midgley, J.T. Klein, N.J. Grigg et al. 2020. 'Expertise in Research Integration and Implementation for Tackling Complex Problems: When is it Needed, Where can it be Found and How can it be Strengthened?' Palgrave Communicatinos 6, Article 5. doi:10.1057/s41599-019-0380-0.

Bateson, G. 1972. Steps to an Ecology of Mind. New York: Ballantine Books.

Berkes, F., J. Colding, and C. Folke. 2003. Navigating Social-Ecological Systems: Building Resilience for Complexity and Change. Cambridge: Cambridge University Press. doi:10.1017/CBO9780511541957.

Berkes, F., and C. Folke. 1998. Linking Social and Ecological Systems. Cambridge: Cambridge University Press.

Biggs, R., M. Schlüter, and M.L. Schoon. 2015. Principles for Building Resilience: Sustaining Ecosystem Services in Social-Ecological Systems. Cambridge: Cambridge University Press. doi:10.1017/ CBO9781316014240.

Blackburn, S., ed. 2008. 'Structuralism.' In Oxford Dictionary of Philosophy (2nd rev ed.), 353. Oxford: Oxford University Press.

Bodin, Ö. 2017. 'Collaborative Environmental Governance: Achieving Collective Action in SocialEcological Systems.' Science 357(6352). doi:10.1126/science.aan1114.

Bodin, Ö., S.M. Alexander, J. Baggio, M.L. Barnes, R. Berardo, G.S. Cumming, L.E. Dee et al. 2019. 'Improving Network Approaches to the Study of Complex Social-Ecological Interdependencies.' Nature Sustainability 2(7): 551-559. doi:10.1038/s41893-019-0308-0.

Boulton, J., P. Allen, and C. Bowman. 2015. Embracing Complexity: Strategic Perspectives for an Age of Turbulence. Oxford: Oxford University Press.

Burns, M.E., M.A. Audouin, and A. Weaver. 2006. 'Advancing Sustainability Science in South Africa.' South African Journal of Science 102: 379-384.

Burns, M., and A. Weaver (eds.). 2008. Exploring Sustainability Science: A Southern African Perspective. Stellenbosch: African SUN MeDIA.

Byrne, D., and G. Callaghan. 2014. Complexity Theory and the Social Sciences: The State of the Art. New York: Routledge.

Capra, F. 2005. 'Complexity and Life.' Theory, Culture \& Society 22(5):33-44. doi:10.1177/0263276405057046.

Capra, F., and P.L. Luisi. 2014. The Systems View of Life. Cambridge: Cambridge University Press. doi:10.1017/CBO9780511895555.

Castellani, B. 2018. Map of the Complexity Sciences. Art \& Science Factory. www.art-sciencefactory. com/complexity-map_feb09.html. 
Chapman, K. 2016. Complexity and Creative Capacity. London: Routledge. doi:10.4324/9781315680767. Checkland, P. 1993. Systems Thinking, Systems Practice. Chichester: John Wiley \& Sons.

Chu, D., R. Strand, and R. Fjelland. 2003. 'Theories of Complexity. Common Denominators of Complex Systems.' Complexity 8(3): 19-30.

Cilliers, P. 1998. Complexity and Postmodernism: Understanding Complex Systems. London: Routledge.

Cilliers, P. 2002. 'Why We Cannot Know Complex Things Completely.' Emergence 4(1-2): 77-84.

Cilliers, P. 2007. Thinking Complexity. Complexity and Philosophy Volume 1. Mansfield: ISCE Publishing.

Cilliers, P. 2008. 'Complexity Theory as a General Framework for Sustainability Science.' In Exploring Sustainability Science. A Southern African Perspective, edited by M. Burns and A. Weaver, 39-57. Stellenbosch: African Sun Media.

Cilliers, P., H.C. Biggs, S. Blignaut, A.G. Choles, J.S. Hofmeyr, G.P W. Jewitt, and D.J. Roux. 2013. 'Complexity, Modeling, and Natural Resource Management.' Ecology and Society 18(3): 1. doi:10.5751/ES-05382-180301.

Clark, W.C. 2007. 'Sustainability Science: A Room of its Own.' Proceedings of the National Academy of Sciences of the USA 104: 1737-1738. doi:10.1073/pnas.0611291104.

Clark, W.C., and A.G. Harley. 2019. Sustainability Science: Towards a Synthesis. Sustainability Science Program Working Paper. John F. Kennedy School of Government, Harvard University, Cambridge, MA.

Cockburn, J., M. Schoon, G. Cundill, C. Robinson, J.A. Aburto, S.M. Alexander, J.A. Baggio et al. 2020. 'Understanding the Context of Multifaceted Collaborations for Social-Ecological Sustainability: A Methodology for Cross-case Analysis.' Ecology and Society 25(3): 7. doi:10.5751/ ES-11527-250307.

De Saussure, F. 1974. Course in General Linguistics. London: Fontana.

De Vos, A., R. Biggs, and R. Preiser. 2019. 'Methods for Understanding Social-Ecological Systems: A Review of Place-based Studies.' Ecology and Society 24(4): 16. doi:10.5751/ES-11236-240416.

Dilthey, W. 1954. The Essence of Philosophy. Translated by S.A. Emery, and W.T. Emery. Chapel Hill: University of North Carolina Press.

Duit, A., and V. Galaz. 2008. 'Governance and Complexity: Emerging Issues for Governance Theory.' Governance 21(3): 311-335.

Folke, C. 2016. 'Resilience' (Republished). Ecology and Society 21(4): 44. doi:10.5751/ES-09088-210444.

Folke, C., S. Carpenter, B. Walker, M. Scheffer, T. Elmqvist, L. Gunderson, and C. S. Holling. 2004. 'Regime Shifts, Resilience, and Biodiversity in Ecosystem Management.' Annual Review of Ecology, Evolution, and Systematics 35: 557-581. doi:10.1146/annurev.ecolsys.35.021103.105711.

Frege, G. 1980. Philosophical and Mathematical Correspondence. Chicago: The University of Chicago Press.

Gelcich, S., T.P. Hughes, P. Olsson, C. Folke, O. Defeo, M. Fernandez, S. Foale et al. 2010. 'Navigating Transformations in Governance of Chilean Marine Coastal Resources.' Proceedings of the National Academy of Sciences 107(39): 16794-16799. doi:10.1073/pnas.1012021107.

Gell-Mann, M. 1994. The Quark and the Jaguar: Adventures in the Simple and the Complex. London: Little, Brown and Company.

Gunderson, L.H., and C.S. Holling. 2002. Panarchy: Understanding Transformations in Human and Natural Systems. Washington: Island Press.

Hahn, T., P. Olsson, C. Folke, and K. Johansson. 2006. 'Trust-building, Knowledge Generation and Organizational Innovations: The Role of a Bridging Organization for Adaptive Co-management of a Wetland Landscape around Kristianstad, Sweden.' Human Ecology 34(4): 573-592. doi:10.1007/ s10745-006-9035-z.

Haider, L.J., W.J. Boonstra, A. Akobirshoeva, and M. Schlüter. 2020. 'Effects of Development Interventions on Biocultural Diversity: A Case Study from the Pamir Mountains.' Agriculture and Human Values 37: 683-697. doi:10.1007/s10460-019-10005-8.

Haider, L.J., J. Hentati-Sundberg, M. Giusti, J. Goodness, M. Hamann, V.A. Masterson, M. Meacham et al. 2018. 'The Undisciplinary Journey: Early-career Perspectives in Sustainability Science.' Sustainability Science 13: 191-204. doi:10.1007/s11625-017-0445-1.

Hammond, D. 2005. 'Philosophical and Ethical Foundations of Systems Thinking.' TripleC 3(2): 20 27. doi:10.31269/triplec.v3i2.20.

Herrfahrdt-Pähle, E., M. Schlüter, P. Olsson, C. Folke, S. Gelcich, and C. Pahl-Wostl. 2020. 'Sustainability Transformations: Socio-political Shocks as Opportunities for Governance Transitions.' Global Environmental Change 63: 102097. doi:10.1016/j.gloenvcha.2020.102097. 
Hertz, T., M. Mancilla García, and M. Schlüter. 2020. 'From Nouns to Verbs: How Process Ontologies Enhance Our Understanding of Social-Ecological Systems Understood as Complex Adaptive Systems.' People and Nature 2(2): 328-338. doi:10.1002/pan3.10079.

Heylighen, F. 1997. 'Publications on Complex, Evolving Systems: A Citation-based Survey.' Complexity 2(5): 31-36.

Holland, J. 1995. Hidden Order: How Adaptation Builds Complexity. Reading: Addison-Wesley.

Holling, C.S. 2001. 'Understanding the Complexity of Economic, Ecological, and Social Systems.' Ecosystems 4(5): 390-405.

Holling, C.S. 2004. 'From Complex Regions to Complex Worlds.' Ecology and Society 9(1): 11. www. ecologyandsociety.org/vol9/iss1/art11.

Joel, J.S. 1983. 'Foreword.' SubStance 12(3): 5-6.

Kauffman, S. 1993. The Origins of Order: Self-organization and Selection in Evolution. New York: Oxford University Press.

Kauffman, S. 2008. Reinventing the Sacred. The Science of Complexity and the Emergence of a Natural Divinity. New York: Basic Books.

Klein, L. 2016. 'Towards a Practice of Systemic Change - Acknowledging Social Complexity in Project Management.' Systems Research and Behavioral Science 33(5): 651-661. doi:10.1002/sres.242.

Kripke, S. 1972. Naming and Necessity. Cambridge: Harvard University Press.

Kuhn, T.S. 1996. The Structure of Scientific Revolutions (3rd ed). University of Chicago Press.

Lacan, J. 2006. Ecrits: The First Complete Edition in English. Translated by B. Fink. New York: W.W. Norton \& Co.

Lade, S.J., L.J. Haider, G. Engström, and M. Schlüter. 2017. 'Resilience Offers Escape from Trapped Thinking on Poverty Alleviation.' Science Advances 3: e1603043.

Lansing, J.S., and J.N. Kremer. 1993. 'Emerging Properties of Balinese Water Temple Networks: Coadaptation on a Rugged Fitness Landscape.' American Anthropologist 95: 97-114. doi: 10.1525/ aa.1993.95.1.02a00050.

Lévi-Strauss, C. 1963. Structural Anthropology. Translated by C. Jacobson and B.G. Schoepf. New York: Basic Books.

Levin, S.A. 1998. 'Ecosystems and the Biosphere as Complex Adaptive Systems.' Ecosystems 1(5): 431436. doi:10.1007/s100219900037.

Levin, S.A. 2000. 'Multiple Scales and the Maintenance of Biodiversity.' Ecosystems 3: 498-506.

Levin, S., T. Xepapadeas, A-S. Crépin, J. Norberg, A. de Zeeuw, C. Folke, T. Hughes et al. 2013. 'Social-Ecological Systems as Complex Adaptive Systems: Modeling and Policy Implications.' Environment and Development Economics 18(2): 111-132. doi:10.1017/S1355770X12000460.

Lewin, R. 1993. Complexity: Life on the Edge of Chaos. London: Phoenix.

Lindkvist, E., X. Basurto, and M. Schlüter. 2017. 'Micro-level Explanations for Emergent Patterns of Self-governance Arrangements in Small-scale Fisheries - A Modeling Approach.' PloS ONE 12: e0175532.

Liu, J., T. Dietz, S.R. Carpenter, M. Alberti, C. Folke, E. Moran, A.N. Pell et al. 2007. 'Complexity of Coupled Human and Natural Systems.' Science 317(5844): 1513-1516. doi:10.1126/ science.1144004.

Mancilla García, M., T. Hertz, M. Schlüter, R. Preiser, and M. Woermann. 2020. 'Adopting Process-relational Perspectives to Tackle the Challenges of Social-Ecological Systems Research.' Ecology and Society 25(1): 29. doi:10.5751/ES-11425-250129.

Martin, R., M. Schlüter, and T. Blenckner. 2020. 'The Importance of Transient Social Dynamics for Restoring Ecosystems beyond Ecological Tipping Points.' Proceedings of the National Academy of Sciences of the United States of America. doi:10.1073/pnas.1817154117.

Max-Neef, M. 2005. 'Foundations of Transdisciplinarity.' Ecological Economics 53: 5-16.

Mazzocchi, F. 2008. 'Complexity in Biology.' EMBO Reports 9(1): 10-14.

Meadows, D.H. 2008. Thinking in Systems. London: Earthscan.

Merchant, C. 1989.The Death of Nature: Women, Ecology, and the Scientific Revolution. New York: Harper \& Row.

Merchant, C. 2018. Science and Nature. Past, Present and Future. New York: Routledge.

Meyers, R., ed. 2009. Encyclopedia of Complexity and Systems Science. Berlin: Springer.

Midgley, G., ed. 2003. Systems Thinking. Volume 1: General Systems Theory, Cybernetics and Complexity. London: Sage.

Mingers, J. 2000. 'The Contribution of Critical Realism as an Underpinning Philosophy for OR/MS and Systems.' Journal of the Operational Research Society 51: 1256-1270. 
Mingers, J. 2006. Realising Systems Thinking: Knowledge and Action in Management Science. New York: Springer.

Mitchell, S. 2004. 'Why Integrative Pluralism?’ E:CO Emergence: Complexity and Organization 6: 81-91.

Moon, K., and D.A. Blackman. 2014. 'Guide to Understanding Social Science Research for Natural Scientists.' Conservation Biology 28(5): 1167-1177. doi:10.1111/cobi.12326.

Morin, E. 1992. 'From the Concept of System to the Paradigm of Complexity.' Journal of Social and Evolutionary Systems 15(4): 371-385.

Morin, E. 2008. On Complexity. Cresskill: Hampton Press.

Morrison, K. 2010. 'Complexity Theory, School Leadership and Management: Questions for Theory and Practice.' Educational Management Administration \& Leadership 38: 374-393.

Newton, I. 1686 [1934]. Mathematical Principles of Natural Philosophy and His System of the World. Translated by W. Motte. Berkeley: University of California Press.

Norberg, J., and G. Cumming. 2008. Complexity Theory for a Sustainable Future. New York: Columbia University Press.

Norgaard, R.B. 1994. Development Betrayed: The End of Progress and a Co-evolutionary Revisioning of the Future. San Francisco: Routledge.

Orach, K., A. Duit, and M. Schlüter. 2020. 'Sustainable Natural Resource Governance under Interest Group Competition in Policy-making.' Nature Human Behaviour 4: 898-909. doi:10.1038/ s41562-020-0885-y.

Österblom, H., B.I. Crona, C. Folke, M. Nyström, and M. Troell. 2017. 'Marine Ecosystem Science on an Intertwined Planet.' Ecosystems 20(1): 54-61. doi:10.1007/s10021-016-9998-6.

Österblom, H., A. Merrie, M. Metian, W.J. Boonstra, T. Blenckner, J.R. Watson, R.R. Rykaczewski et al. 2013. 'Modeling Social-Ecological Scenarios in Marine Systems.' BioScience 63(9): 735-744. doi:10.1525/bio.2013.63.9.9.

Ostrom, E. 1990. Governing the Commons. The Evolution of Institutions for Collective Action. New York: Cambridge University Press.

Piaget, J. 1985. The Equilibration of Cognitive Structures: The Central Problem of Intellectual Development. Chicago: University of Chicago Press.

Poli, R. 2013. 'A Note on the Difference between Complicated and Complex Social Systems.' Cadmus 2(1): 142-147.

Popper, K. 1972. Objective Knowledge: An Evolutionary Approach. Oxford: Clarendon Press.

Preiser, R. 2019. 'Identifying General Trends and Patterns in Complex Systems Research: An Overview of Theoretical and Practical Implications.' Systems Research and Behavioral Science 36: 706-714. doi:10.1002/sres.2619 RESEARCH.

Preiser, R., R. Biggs, A. de Vos, and C. Folke. 2018. 'Social-Ecological Systems as Complex Adaptive Systems: Organizing Principles for Advancing Research Methods and Approaches.' Ecology and Society 23(4): 46. doi:10.5751/ES-10558-230446.

Preiser, R., and P. Cilliers. 2010. 'Unpacking the Ethics of Complexity: Concluding Reflections.' In Complexity, Difference and Identity, edited by P. Cilliers and R. Preiser, 265-287. Dordrecht: Springer. doi:10.1007/978-90-481-9187-1_13.

Prigogine, I. 1996. The End of Certainty: Time, Chaos, and the New Laws of Nature. New York: Free Press.

Rajagopalan, R., and G. Midgley. 2015. 'Knowing Differently in Systemic Intervention.' Systems Research and Behavioral Science 32(5): 546-561. doi:10.1002/sres.2352.

Ramage, M., and K. Shipp, eds. 2009. Systems Thinkers. London: Springer.

Rasch, W. 1991. 'Theories of Complexity, Complexities of Theory: Habermas, Luhmann, and the Study of Social Systems.' German Studies Association 14(1): 65-83.

Rasch, W., and E.M. Knodt. 1994. 'Systems Theory and the System of Theory.' New German Critique 61(Special Issue on Niklas Luhmann): 3-7.

Rasch, W., and C. Wolfe, eds. 2000. Observing Complexity: Systems Theory and Postmodernity. Minneapolis: University of Minneapolis Press.

Rescher, N. 1998. Complexity: A Philosophical Overview. New Brunswick: Transactions.

Reyers, B., J.L. Nel, P.J. O'Farrell, N. Sitas, and D.C. Nel. 2015. 'Navigating Complexity through Knowledge Coproduction: Mainstreaming Ecosystem Services into Disaster Risk Reduction.' Proceedings of the National Academy of Sciences 112(24): 7362-7368. doi:10.1073/pnas.1414374112.

Rogers, K.H., R. Luton, H. Biggs, R. Biggs, S. Blignaut, A.G. Choles, C.G. Palmer, and P. Tangwe. 2013. 'Fostering Complexity Thinking in Action Research for Change in Social-Ecological Systems.' Ecology and Society 18(2): 31. doi:10.5751/ ES-05330-180231. 
Rosen, R. 1991. Life Itself: A Comprehensive Enquiry into the Nature, Origin, and Fabrication of Life. New York: Columbia University Press.

Rousseau, D. 2017. 'Systems Research and the Quest for Scientific Systems Principles.' Systems 5(2): 25. doi:10.3390/ systems5020025.

Russel, B. 1945. A History of Western Philosophy. New York: Simon \& Schuster.

Schlüter, M., J. Haider, S.J. Lade, E. Lindkvist, and R. Martin. 2019a. 'Capturing Emergent Phenomena in Social-Ecological Systems: An Analytical Framework.' Ecology and Society 24(3): 11. doi:10.5751/ES-11012-240311.

Schlüter, M., K. Orach, E. Lindkvist, R. Martin, N. Wijermans, O. Bodin, and W.J. Boonstra. 2019b. 'Toward a Methodology for Explaining and Theorizing about Social-Ecological Phenomena.' Current Opinion in Environmental Sustainability 39: 44-53. doi:10.1016/j.cosust.2019.06.011.

Schlüter, M., and C. Pahl-Wostl. 2007. 'Mechanisms of Resilience in Common-pool Resource Management Systems: An Agent-based Model of Water Use in a River Basin.' Ecology and Society 12(2): 4. www.ecologyandsociety.org/vol12/iss $2 / \operatorname{art} 4 /$.

Schoon, M., and S. van der Leeuw. 2015. 'The Shift toward Social-Ecological Systems Perspectives: Insights into the Human-Nature Relationship.' Natures Sciences Sociétés 23(2): 166-174. doi:10.1051/ nss/2015034.

Tarski, A. 1959. Introduction to Logic and to the Methodology of Deductive Sciences (8th ed). New York: Oxford University Press.

Tengö, M., E.S. Brondizio, T. Elmqvist, P. Malmer, and M. Spierenburg. 2014. 'Connecting Diverse Knowledge Systems for Enhanced Ecosystem Governance: The Multiple Evidence Base Approach.’ Ambio 43(5): 579-591. doi:10.1007/s13280-014-0501-3.

Thrift, N. 1999. 'The Place of Complexity.' Theory, Culture \& Society 16(3): 31-69.

Thurner, S., R. Hanel, and P. Klimek. 2018. Introduction to the Theory of Complex Systems. Oxford: Oxford University Press.

Toulmin, S. 2001. Return to Reason. Cambridge: Harvard University Press.

Ulanowicz, R. 1999. 'Life after Newton: An Ecological Metaphysic.' Biosystems 50(2): 127-142.

Ulanowicz, R. 2007. 'Ecology: A Dialogue between the Quick and the Dead.' In Exploring Complexity. Volume 1: Reframing Complexity. Perspectives from the North and South, edited by F. Capra, A. Juarerro, P. Sotolongo, and J. van Uden. Mansfield: ISCE Publishing.

Ulanowicz, R. 2009. A Third Window: Natural Life Beyond Newton and Darwin. West Conshohocken: Templeton Foundation Press.

Ulrich, W. 1994. 'Can We Secure Future-responsive Management through Systems Thinking and Design?' Interfaces 24(4): 26-37. doi:10.1287/inte.24.4.26.

Ulrich, W. 2000. 'Reflective Practice in the Civil Society: The Contribution of Critically Systemic Thinking.' Reflective Practice 1(2): 247-268. doi:10.1080/713693151.

Urry, J. 2005. 'The Complexity Turn.' Theory, Culture \& Society 22(5): 1-14.

Von Bertalanffy, L. 1968. General System Theory: Foundations, Development, Applications. New York: George Braziller.

Von Foerster, H. 1960. 'On Self-organising Systems and their Environments.' In Self-Organising Systems, edited by M.C. Yovits and S. Cameron, 30-50. London: Pergamon Press.

Waldrop, M. 1993. Complexity: The Emerging Science at the Edge of Order and Chaos. New York: Simon \& Schuster.

Walker, B., C.S. Holling, S.R. Carpenter, and A. Kinzig. 2004. 'Resilience, Adaptability and Transformability in Social-Ecological Systems.' Ecology and Society 9(2): 5. doi:10.5751/ES-00650-090205.

Wells, J.L. 2013. Complexity and Sustainability. New York: Routledge.

Wittgenstein, L. 1953. Philosophical Investigations, edited by G.E.M. Anscombe and R. Rhees. Translated by G.E.M. Anscombe. Oxford: Blackwell.

Woermann, M. 2016. Bridging Complexity and Post-Structuralism. Insights and Implications. Switzerland: Springer. doi:10.1007/978-3-319-39047-5.

Wolfram, S. 2002. A New Kind of Science. Champaign: Wolfram Media. 